\title{
FRESH METHOD: 3D BIOPRINTING AS A NEW APPROACH FOR TISSUE AND ORGAN REGENERATION
}

\author{
Alena Findrik Balogová \\ Department of Biomedical Engineering and measurement, Faculty of Mechanical Engineering, Letná 1/9, 042 00, \\ Košice, Slovakia, EU, alena.findrik.balogova@tuke.sk (corresponding author) \\ Marianna Trebuňová \\ Department of Biomedical Engineering and measurement, Faculty of Mechanical Engineering, Letná 1/9, 042 00, \\ Košice, Slovakia, EU, marianna.trebunova@tuke.sk \\ Viktória Rajt'úková \\ Department of Biomedical Engineering and measurement, Faculty of Mechanical Engineering, Letná 1/9, 042 00, \\ Košice, Slovakia, EU, viktoria.rajtukova@tuke.sk

\section{Radovan Hudák} \\ Department of Biomedical Engineering and measurement, Faculty of Mechanical Engineering, Letná 1/9, 042 00,
} Košice, Slovakia, EU, radovan.hudak@tuke.sk

Keywords: FRESH, bioprinting, hydrogel, 3D printing

Abstract: Over the last decade, techniques of additive manufacturing of biomaterials have undergone a transformation, from a fast prototype tool used in research and development, to a viable approach in the production of customised medical devices. The key to this transformation is the ability of additive manufacturing to precisely define the structure and properties of a material in three dimensions, and to adjust those properties to unique anatomical and physiological criteria based on the medical data obtained by Computed Tomography (CT) and Magnetic Resonance Imaging (MRI).

The 3D bioprinting technique was developed as a solution to provide temporary and ubiquitous support of structures during the printing process. In general, integrated 3D printing may be understood as a building chamber that is filled with bearing materials, where biomaterials, cellular spheroids, cell-laden hydrogels and other materials (bioinks) are deposited using a syringe-based extruder. In particular, FRESH 3D bioprinting is a revolutionary technology, which may bring a fast and efficient advancement to medicine thanks to the ability to print new tissues from live cells.

\section{Introduction}

Over the last decade, additive manufacturing techniques for biomaterials have undergone a transformation, from a fast prototype tool used in research and development, to a viable approach in the production of customised medical devices. The key to this transformation is the ability of additive manufacturing to precisely define the structure and properties of a material in three dimensions, and to adjust those properties to unique anatomical and physiological criteria based on the medical data obtained by Computed Tomography (CT) and Magnetic Resonance Imaging (MRI).

The 3D bioprinting technique was developed as a solution to provide temporary and ubiquitous support of structures during the printing process. In general, integrated 3D printing may be understood as a building chamber that is filled with bearing materials, where biomaterials, cellular spheroids, cell-laden hydrogels and other materials (bioinks) are deposited using a syringebased extruder. In particular, FRESH 3D bioprinting is a revolutionary technology, which may bring a fast and efficient advancement to medicine thanks to the ability to print new tissues from live cells [1].

\section{3D bioprinting techniques}

There are several 3D bioprinting techniques which are currently used in the fabrication of $3 \mathrm{D}$ tissues. The following three basic approaches are the most frequently used (Figure 1):

1. Extrusion-based bioprinting.

2. Inkjet bioprinting.

3. Laser-assisted bioprinting.

The extrusion-based bioprinting is a technology based on using jets and the printing process requires mechanical pressure for the controlled and continuous extrusion of bioinks through the syringe jet. Materials may be extruded in three ways, in particular using the air (pneumatically), a piston, or a screw. The most promising properties of this technology include the universality of the choice of materials within a wide range of bioinks and the highprecision production of chemically relevant tissues or organs. Optimisation of the jet diameter is the main parameter of the printing process for a particular hydrogel. A low-diameter jet for viscous hydrogel requires high pressure, and high extrusion pressure increases the shearing stress of cells. At a higher shearing stress, cellular damage may occur and this may reduce the life cycle of the 
FRESH METHOD: 3D BIOPRINTING AS A NEW APPROACH FOR TISSUE AND ORGAN REGENERATION

Alena Findrik Balogová; Marianna Trebuňová; Viktória Rajtúková; Radovan Hudák

cells after the printing. The pneumatic approach provides reduced cellular damage due to a lower shearing stress during the printing process [2][3].

The inkjet bioprinting is a $3 \mathrm{D}$ bioprinting technology which is based on a conventional process of ink printing. It is a contactless printing process in which bioink droplets are deposited onto a hydrogel substrate or a culture dish under computer control. The common methods can be further classified into thermal and piezoelectric actuator methods based on the droplet actuation mechanism [4].

In the thermal technology, heating causes gasification and formation of bubbles. Inflated bubbles force the ink out of a narrow nozzle and onto the substrate. In piezoelectric technology, droplets are generated by the transient pressure from a piezoelectric actuator. The piezoelectric method does not use heat and does not cause orifice clogging, thus allowing droplets to remain directional while maintaining a regular and constant size [5].

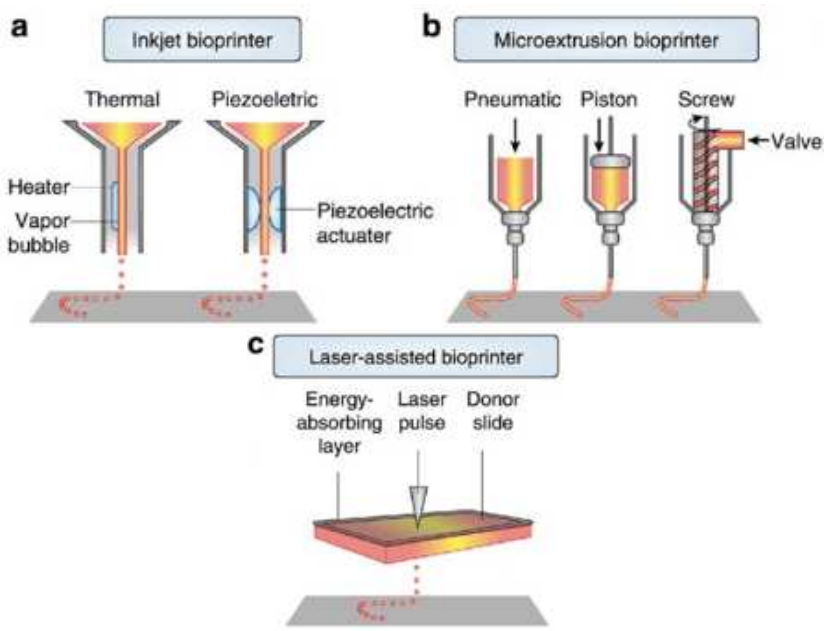

Figure 1 Basic principles of 3D bioprinting [6]

The third method is the laser-assisted bioprinting. This technology consists of directing laser impulses through the layers of materials containing also bioink onto a substrate. The substrate is coated with a layer of titanium or gold that absorbs the laser energy to avoid cellular damage. The lower section of the layers contains cells and a biomaterial, which together form a high-pressure bubble following the evaporation induced by a laser impulse. The bubble propels the bioink layer and forms droplets in order to facilitate depositing bioink onto the substrate [7].

\section{Commonly used materials for bioprinting}

The 3D bioprinting of tissues or organs is usually carried out using hydrogel materials (Figure 2). Hydrogels are materials capable of holding a mass of water. The development of first hydrogels dates back to 1950s, when contact lenses were developed. Hydrogel is a hydrophilic polymer material holding a great amount of water while maintaining its structure thanks to chemical or physical cross-linking of the individual polymer chains. Hydrogels also exhibit high elasticity, similar to tissue elasticity, as they contain large amounts of water [8].

Hydrogels possess many attractive properties which are suitable for the application of hydrogels as tissue scaffolds. For example, they are biocompatible and typically biodegradable, majority of them having specific cellbonding sites which are necessary to adhere, proliferate, grow and differentiate. Furthermore, some of these biomaterials may easily be cross-linked when present in modified forms [9].

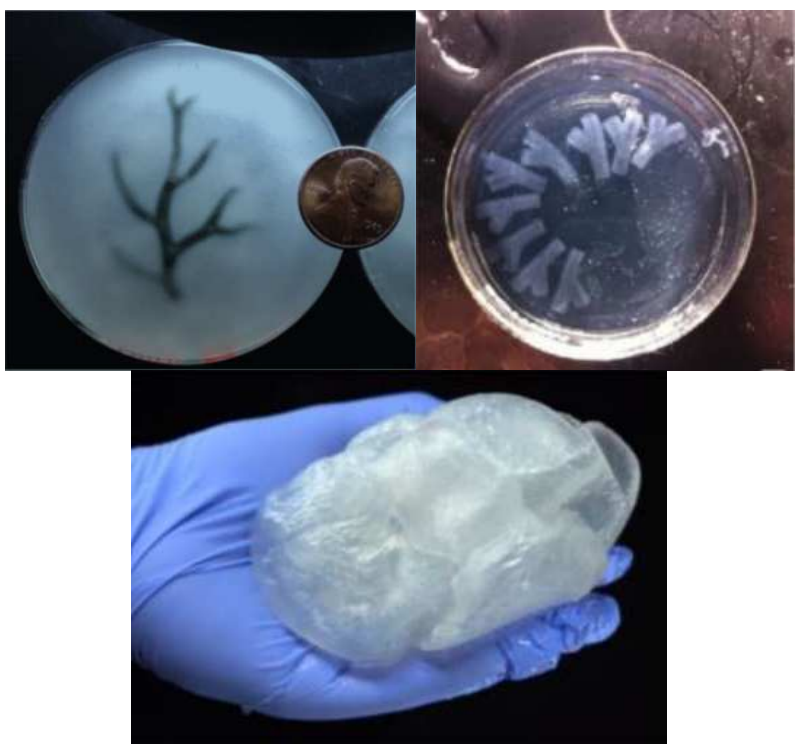

Figure $23 D$ printing of anatomical structures from hydrogel

Bioinks are solutions from biomaterials that contain encapsulated living cells and are the basis of bioprinting. It is important that such materials contained in biomaterial solutions protect cells from mechanical deformation during the printing process, provide them with nutrients and allow them to proliferate [10].

Collagen is a major building block found in mammalian cells, specifically in the extracellular matrix, making it an attractive material for applications in biomedical engineering, tissue engineering and regenerative medicine. it has similar physicochemical properties to tissues and, due to its biocompatibility, is widely used in both in vivo and in vitro applications. Type I collagen has been applied using the FRESH method and is the most common type of collagen. It represents up to $90 \%$ of collagen in the skin, tendons, bones and elsewhere in organisms [11].

Gelatin Gelatin is produced by denaturing collagen, for example, from the bones, tendons or skin of animals by acidic or basic hydrolysis. Due to its properties such as thermosensitivity and the ability to form a hydrogel at lower temperatures depending on the concentration, it is one of the most commonly used natural polymers. In addition to biocompatibility, biodegradability, the 
advantages of gelatin include low antigenicity, the absence of harmful by-products, easy processing and low costs. All these properties, and in particular its cellular affinity, make it a universal material for applications in tissue engineering and bioprinting [11].

Hyaluronic acid (HA) is a hydrophilic linear anionic polysaccharide composed of 1,3- $\beta$-D-glucuronic acid and $1,4-\beta$-Nacetyl-D-glucosamine. It is a major component in the extracellular matrix (ECM), where it plays a crucial role in maintaining cartilage homeostasis by regulating cellular functions and the production and retention of matrix components. It is found in most tissue binders in all living organisms. HA is currently used as a lubricant and in healthcare to prevent postoperative adhesions. Because HA is naturally present in tissues, it can be used to encapsulate cells [12][13].

Alginate is a natural polysaccharide - a natural anionic polysaccharide refined from brown seaweed and is similar to the glycosaminoglycans found in the native ECM of the human body [12].

Chitosan has been studied in recent years for various tissue engineering applications due to its biocompatibility, biodegradability, low immunogenicity and also cationic nature. Thanks to these properties, it is a promising biomaterial for tissue engineering applications. The higher degree of deacetylation of the chitin chain promotes the biocompatibility of these hydrogels [10].

\section{The principle of the FRESH 3D bioprinting}

FRESH (Freeform Reversible Embedding of Suspended Hydrogels) technology is based on the principle of extruding biomaterial from the reservoir syringe in its liquid form into a support bath, where the biomaterial must polymerize rapidly. This polymerization process occurs by rapid crosslinking of the polymer molecules, and this crosslinking mechanism depends on the type of 3D printed hydrogel (Figure 3) [9].

FRESH uses a thermoreversible support bath, which allows the deposition of hydrogels in 3D biological structures of the desired shape. The benefit of the FRESH method is the storage and insertion of hydrogels or bioinks, which have been 3D printed in a second hydrogel support bath, which retains the desired shape during the printing process and significantly improves print fidelity [13].

The support bath and thus the hydrogel is placed in a container of the desired size, consisting of gelatin particles which act as a Bingham plastic during the printing process. This means that at low shear stresses they behave like a solid body, but at higher shear stresses they flow like a viscous fluid. When the needle nozzle moves through the bath, there is little mechanical resistance; nevertheless, the hydrogel is expelled from the nozzle and stored in the bath held in place. In this step, the gelatin suspension is maintained at $22{ }^{\circ} \mathrm{C}$ in order to preserve its rheological properties. Soft materials that would collapse when printed in air are therefore easily maintained in the intended 3D geometry. The whole process takes place in a sterile, aqueous, buffered medium biocompatible for the cells used [9].

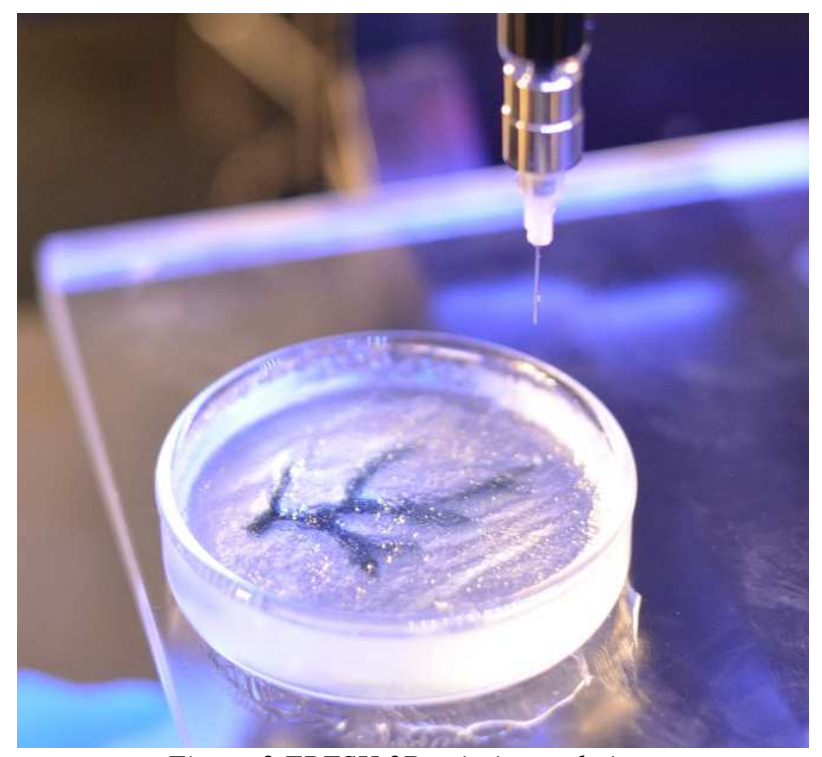

Figure 3 FRESH 3D printing technique

Once the entire 3D structure is FRESH printed, the temperature is raised to a cell-friendly $37{ }^{\circ} \mathrm{C}$; this causes that the gelatine support bath melts for used printed cells in bioink in a non-destructive manner. FRESH therefore enables direct 3D printing of biologically relevant hydrogel inks, including alginate, fibrin, type I collagen, and Matrigel, within a support bath designed to be removed afterwards [14].

The most common material selected for use as a supportive bath is gelatin. It is also suitable due to its biocompatible properties, because it is never possible to remove $100 \%$ of the support bath from the extruded structure. Even because of its origin in collagen, it is able to bind to polysaccharides and other ECM proteins. Thus, the residual amount of support bath does not adversely affect cell integration, but may increase cell adhesion.

\section{Conclusions}

The main challenge in tissue engineering and regenerative medicine is the production of functional tissues and organs to compensate for a limited number of transplant donors. Until now, most 3D bioprinted tissue constructs were relatively small when compared to tissues or organs that need to be replaced. This is partially caused by the problems associated with $3 \mathrm{D}$ bioprinting of soft materials and cells. Therefore, FRESH printing has the potential to become the technology for manufacturing models which will facilitate complete fabrication of tissues based on patient-specific anatomical data. 


\section{Acknowledgement}

The present paper was prepared with the support from the KEGA Project No. 023TUKE-4/2020 "Increasing the synergy of methods of teaching biophysics using laboratory equipment and diagnostic devices aimed at measuring physical and technical quantities". This publication was prepared with the support from the Integrated Infrastructure Operational Programme for the project: "Center for advanced therapies for chronic inflammatory diseases of the musculoskeletal system" (CPT ZOPA), code ITMS2014+: 313011W410, cofinanced from the European Regional Development Fund. This publication was prepared with the support from the Integrated Infrastructure Operational Programme for the project: "Open scientific community for modern interdisciplinary research in medicine" (OPENMED), code ITMS2014+: 313011V455, co-financed from the European Regional Development Fund. This publication was created thanks to support under the Operational Program Integrated Infrastructure for the project: Center for Advanced Therapies of Chronic Inflammatory Diseases of the Locomotion System (CPT ZOPA), ITMS2014+: 313011W410, co-financed by the European Regional Development Fund.

\section{References}

[1] SHIWARSKI, D.J., HUDSON, A.R., TASHMAN, J.W., FEIBERG, A.W.: Emergence of FRESH 3D printing as a platform for advanced tissue biofabrication, APL Bioengineering, Vol. 2021, No. February, 2021. doi:10.1063/5.0032777

[2] CHAN, W.W., YEO, D.CH.L., TAN, V., SINGH, S., CHOUDHURY, D., NAING, M.W.: Additive Biomanufacturing with Collagen Inks, Bioengineering, Vol. 7, No. 3, pp. 1-23, 2020. doi:10.3390/bioengineering7030066

[3] DAS, S., BASU, B.: An Overview of Hydrogel-Based Bioinks for 3D Bioprinting of Soft Tissues, Journal of the Indian Institute of Science, Vol. 99, No. 3, pp. 405428, 2019.

[4] ZHU, W., MA, X., GOU, M., MEI, D., ZHANG, K., CHEN, S.: 3D printing of functional biomaterials for tissue engineering, Current Opinion in Biotechnology, Vol. 40, No. August, pp. 103-112, 2016. doi:10.1016/j.copbio.2016.03.014

[5] LI, J., CHEN, M., FAN, X., ZHOU, H.: Recent advances in bioprinting techniques: approaches, applications and future prospects, Journal of Translational Medicine, Vol. 14, No. September, 2016. doi:10.1186/s12967-016-1028-0

[6] WENG, T., ZHANG, W., XIA, Y., WU, P., YANG, M., JIN, R., XIA, S., WANG, J., YOU, CH., HAN, CH., WANG, X.: 3D bioprinting for skin tissue engineering: Current status and perspectives, Journal of Tissue Engineering, Vol. 12, No. June, pp. 1-28, 2021. doi:10.1177/20417314211028574
[7] DU TOIT, L., KUMAR, P., CHOONARA, Y., PILLAY, V.: Advanced 3D-Printed Systems and Nanosystems for Drug Delivery and Tissue Engineering, Woodhead Publishing, 2020.

[8] BENNING, L., GUTZWEILER, L., TRONDLE, K., RIBA, J., ZENGERLE, R., KOLTAY, P., ZIMMERMANN, S., STARK, G.B., FINKENZELLER, G.: Assessment of hydrogels for bioprinting of endothelial cells, Journal of Biomedical Materials Research Part A, Vol. 106, No. 4, pp. 935947, 2017.

[9] BAHRAM, M., MOHSENI, N., MOGHTADER, M.: An Introduction to Hydrogels and Some Recent Applications, IntechOpen, 2016. doi:10.5772/64301

[10] GUNGOR-OZKERIM, P.S., INCI, I., ZHANG, Y.S., KHADEMBOSSEINI, A., DOKMECI, M.R.: Bioinks for 3D bioprinting: an overview, Biomater Sci, Vol. 6, No. 5, pp. 915-946, 2018. doi:10.1039/c7bm00765e

[11] BENNING, L., Gutzweiler, L., Tröndle, K., Riba, J., Zengerle, R., Koltay, P., Zimmermann, S., Stark, G.B., Finkenzeller, G.: Assessment of hydrogels for bioprinting of endothelial cells, J Biomed Mater Res, Part A, Vol. 106, No. 4, pp. 935-947, 2018. doi:10.1002/jbm.a.36291

[12] ANTICH, C., de VICENTE, J., JIMENEZ, G., CHOCARRO, C., CARRILLO, E., MONTANEZ, E., GALVEZ-MARTIN, P., MARCHAL, J.A.: Bioinspired hydrogel composed of hyaluronic acid and alginate as a potential bioink for 3D bioprinting of articular cartilage engineering constructs, Acta Biomaterialia, Vol. 106, No. April, pp. 114-123, 2020. doi:10.1016/j.actbio.2020.01.046

[13] FEDOROVICH, N.E., ALBLAS, J., de WIJN, J.R., HENNINK, W.E., VERBOUT, A.J., DHERT, W.J.A.: Hydrogels as Extracellular Matrices for Skeletal Tissue Engineering: State-of-the-Art and Novel Application in Organ Printing, Tissue Engineering, Vol. 13, No. 8, pp. 1905-1925, 2007. doi:10.1089/ten.2006.0175

[14] HINTON, T.J., Jallerat, Q., Palchesko, R.N., Park, J.H., Grodzicki, M.S., Shue, H.J., Ramadan, M.H., Hudson, A.R., Feinberg, A.W.: Three-dimensional printing of complex biological structures by freeform reversible embedding of suspended hydrogels, Science Advances, Vol. 1, No. 9, pp. 1-10, 2015. doi:10.1126/sciadv. 1500758

[15] MIRDAMADI, E., TASHMAN, J.W., SHIWARSKI, D.J., PALCHESKO, R.N., FEINBERG, A.W.: FRESH 3D Bioprinting a Full-Size Model of the Human Heart, ACS Biomaterial Science Engineering, Vol. 6, No. 11, pp. 6453-6459, 2020. doi:10.1021/acsbiomaterials.0c01133

\section{Review process}

Single-blind peer review process. 